\title{
AGE-HARDENING AND RELATED PHASE TRANSFORMATIONS IN DENTAL GOLD ALLOYS
}

\author{
Katsuhiro Yasuda \\ Department of Dental Materials Science, Nagasaki University School of Dentistry, \\ Nagasaki, Japan
}

Gold alloys that can be hardened by thermal ageing play an important role in dentistry. But the ordering and precipitation phenomena responsible for hardening are complex and not fully understood. In this comprehensive survey of the field, the author shows that transmission electron microscopy coupled with electron diffraction measurements is a powerful tool for studying age-hardening mechanisms in dental gold alloys.

It has been known for or a long time that an age-hardening phenomenon occurs in several types of dental gold alloys. However, the causes of this hardening, and the nature of the related phase transformations, have not been extensively studied until fairly recently. This is not surprising, for it is difficult to elucidate the hardening mechanisms of alloys as complex as dental gold alloys, which are often composed of 5 or more elements.

Progress in metallurgy and materials science has been rapid during the last decade, because electron microscopy has made it possible to study directly the relationship between microstructure and phase transformations in alloys. In particular, high resolution electron microscopic observation coupled with the selected-area electron diffraction technique has enabled us to readily analyse age-hardening mechanisms in dental gold alloys. This work has contributed to a better understanding of the phenomenon, and has led to the clarification of a number of questions of great practical importance. There is a consensus among investigators

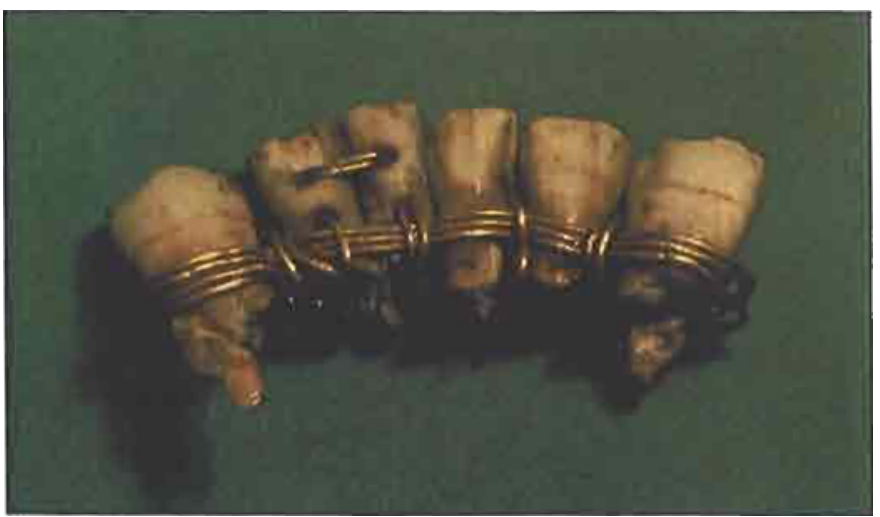

Fig. 1 Retentive prosthesis supposedly of Phoenician origin. Louvre Museum, Paris
The main object of this article is, therefore, to review the significant findings of transmission electron microscopy (TEM) concerning age-hardening and structural transformations in dental gold alloys.

\section{Historical Background}

\section{From Pure Gold to Complex Gold Alloys}

Gold is one of the oldest materials used in dental practice. For instance, the early Phoenician restoration known as the Gaillardot specimen (1), dating from about $600-400 \mathrm{BC}$, is an interesting example of the use of gold wire to maintain teeth in a fixed position (Figure 1). This specimen is now in the possession of the Louvre Museum in Paris. Another early example is the Etruscan bridgework-type appliance for supporting loose teeth, which was made of gold strip; it was illustrated in the paper by Donaldson in this journal (2). Obviously, the gap left by the loss of a tooth caused a problem that was more a question of hurt vanity than of an inability to masticate. The skill in making dental appliances from gold wire or strip was highly in this field that a more fundamental understanding of phase transformations is necessary for developing new alloys for dentistry, and for explaining the mechanical, chemical and biological properties of dental alloys. developed among the Egyptians, Phoenicians and Etruscans, later period. and was extensively practised by the Greeks and Romans of a 
In early times, relatively pure, unalloyed goId in the form of wire or sheet was used for making dental appliances. One of the earliest gold alloys to be used in dentistry was a simple coin gold alloy popular in the United States. Containing 90 weight per cent gold and 10 weight per cent copper, the alloy was really too soft to be suitable for serious dental applications.

At the beginning of the 1900 s, the price of platinum was lower than that of gold. So in order to reduce the cost of dental gold alloys, attempts were made to replace a proportion of the gold with a corresponding amount of platinum. In the 1920s, however, platinum again became more expensive than gold. But the gold alloys containing platinum have been used continuously to this day in spite of their high cost, because of their extremely high chemical stability in the mouth and their desirable mechanical properties such as high strength, ductility and elasticity.

In 1926, Coleman showed

that the compositions of dental gold alloys in use at that time could be grouped into four types, each having slightly different properties (3). Thereafter, the gold alloys described by Coleman became the basis for the American Dental Association's Specification for dental gold casting alloys, in which they are normally classified as Type I through Type IV, according to their gold and platinum metals content, and their mechanical properties (i.e. 'soft', 'medium', 'hard' and 'extra-hard'). The Type IV alloys are designed to be age-hardenable by an appropriate heat treatment.

Progress in metallurgy, as well as economic considerations, have resulted in a wide selection of gold-copper-silver based alloys being available for dentistry. Among them there are several low gold-content alloys with mechanical properties almost equal to those found in high gold-content alloys. A silver-based gold-silver-palladium alloy, which is employed extensively in Japan, exhibits properties similar to those of the gold-based alloys, except for corrosion resistance. The compositions of these alloys are indicated by their location in the pseudo-ternary diagram shown in Figure 2. It can be seen that precious metal alloys for dental applications fall into three distinct classes according to their composition, namely high gold-content alloys, low gold-content alloys, and silver-based gold-silver-palladium alloys.

\section{Age-Hardening in Dental Gold Alloys}

At present, it is well known that desirable mechanical properties in a gold alloy containing platinum or palladium may be obtained by controlling the phase transformations brought about by appropriate heat treatment.

In 1860 Campbell, a dental practitioner in Fulton, New York, reported on a new alloy, produced by adding platinum to coin gold, which had better tarnish resistance than the dental gold alloys commonly used at that time (4). This is believed to be the earliest reference to a dental gold alloy containing platinum. An age-hardenable gold-platinum-copper-silver alloy, in which the 
hardening effect was thought to be due to the formation of a AuCu superlattice, was developed and put on the market for the first time by the S.S. White Dental Manufacturing Company in 1905-6. It is astonishing to note that age-hardening was being applied in dental practice so early on, for it was not until 1906 that Wilm's paper (5) on the phenomenon of hardening in an aluminum-magnesium alloy, after quenching from high temperature, was published.

The various formulations of commercial dental gold alloys were developed largely by empirical methods. The amount of platinum and/or palladium in the alloys was influenced by the relative market prices of the platinum group metals. This resulted in the production of what appeared to be extremely complex alloys, frequently containing five or more constituents. Yet very little in-depth work on these complex alloys, aimed at establishing their constitution, the precise age-hardening mechanisms, or other physico-metallurgical aspects, was carried out.

However, by 1932, Wise et al. had investigated the improvements in strength, hardenability and colour which could be obtained by replacing some of the gold in a typical gold-copper-silver alloy with varying amounts of platinum or palladium. They showed that the addition of either platinum or palladium to a gold-copper-silver ternary alloy resulted in a considerable increase in strength after an appropriate heat treatment. Furthermore, they studied a wide variety of such alloys employing metallographic and $X$-ray diffraction techniques. They were able to identify phase separation and precipitation phenomena, as well as ordering, in a number of ternary gold-copper-silver and quaternary gold-copper-silver-platinum or palladium alloys
$(6,7)$. It was clear from their work that the formation of a $\mathrm{AuCu}$ superlattice is essential to the age-hardening process, and that precipitation played a subordinate part.

In 1972, Leinfelder and his associates reported studies of the hardening mechanism in commercial dental gold alloys and in the stoichiometric AuCu binary alloy. By measuring the alloys' hardness and the degree-of-ordering parameter as a function of ageing time, they were able to correlate hardening with the rate of ordering (8). Their hypothesis was that the hardening might be associated with the formation of very fine coherent precipitates. They also reported that age-hardening in ternary gold-copper-silver alloys, and in commercial dental gold alloys outside the two-phase region of the ternary gold-copper-silver system, was also due to ordering. On the other hand, in the case of alloys within the two-phase region, hardening occurred partly by ordering, and partly through some other mechanism (apart from grain boundary precipitation) (9).

$\mathrm{X}$-ray diffraction studies, however, do not give direct information on the correlation between structural and morphological changes during the ageing process. Although TEM has proven to be an indispensable technique for unravelling the agehardening mechanisms and related structural changes in dental gold alloys, papers dealing with these mechanisms from the standpoint of crystallography did not appear until 1975 (see below).

\section{The AuCu I and AuCu II Superlattices in the Binary Gold-Copper System}

In gold-copper alloys near the equiatomic composition, the solid solution possesses a face-centered cubic (f.c.c.) lattice, and is stable above $683 \mathrm{~K}\left(410^{\circ} \mathrm{C}\right)$ (Figure 3a), while at lower temperatures the equilibrium state is complicated by the presence of two ordered crystallographic structures (AuCu $\mathrm{I}$ and $\mathrm{AuCu} \mathrm{II})$. Below $658 \mathrm{~K}$ $\left(385^{\circ} \mathrm{C}\right)$, the stable arrangement for the alloy is a face-centred tetragonal (f.c.t.) lattice, $\mathrm{AuCu} \mathrm{I}$, where alternate $(002)$ planes are occupied by either all gold or all copper atoms, as shown in Figure $3 \mathrm{~b}$. On account of the differing atomic radii of the two constituents, this arrangement results in a distortion of the lattice from f.c.c. to f.c.t.

When the AuCu I ordering proceeds in the alloy, a considerable amount of strain as-
Fig. 3 Schematic representation of the AuCu I superlattice. (a) shows the disordered state which has a f.c.c. structure, (b) is the unit cell of the AuCu I superlattice, which has a f.c.t. structure. Open and solid circles indicate gold atoms and copper atoms, respectively 
sociated with the change in crystal symmetry may develop in the surrounding matrix. Nowack (10) showed that the hardness of a binary $\mathrm{AuCu}$ alloy at first increased markedly upon ageing at $473 \mathrm{~K}\left(200^{\circ} \mathrm{C}\right)$, but softening began to occur after longer ageing periods. An experiment conducted by Harker (11) on AuCu indicated that the initial strain associated with the development of small tetragonally ordered domains could lead to substantial hardening. Subsequently, Kuczynski and coworkers observed, using optical microscopy, that a

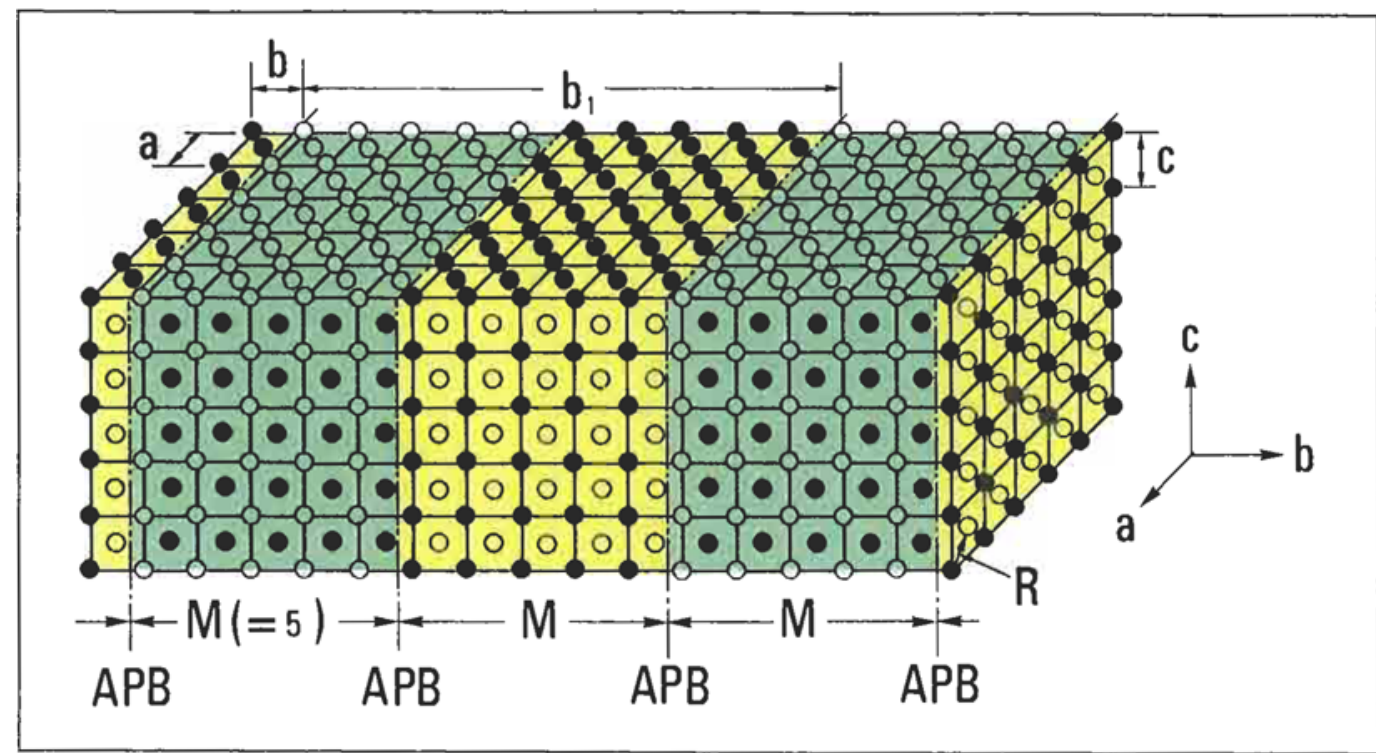

Fig. 4 The arrangement of antiphase domain boundaries in the long-period superlattice of AuCu II. Open and solid circles indicate gold atoms and copper atoms, respectively

$(110)_{\text {cub }}$ plane in the disordered phase was the preferred twinning plane, with (101) tet as the conjugate plane in the ordered AuCu I phase (12). Hirabayashi and Weissmann used TEM to study the twin lamellae that occurred in the equiatomic goldcopper alloy using thin foil specimens prepared from the bulk material (13). They confirmed that the twin boundary was parallel to (101)tet and that the alternation of the c-axis of the AuCu I lattice occurred in the sequence $X Y X Y$..., or YZYZ..., or $Z X Z X$..., where the directions of $X, Y$ and $Z$ are perpendicular to each other and parallel to the original cube axes.

As the ordered domains grow larger in size, the strain field in the matrix becomes too great to be accommodated simply by a distortion of the lattice planes. When this happens, the strain field is released by the occurrence of twinning. Thus, the softening effect after prolonged ageing in the binary alloy is due to twinning.

The superlattice formed at temperatures between $658 \mathrm{~K}$ $\left(385^{\circ} \mathrm{C}\right)$ and $683 \mathrm{~K}\left(410^{\circ} \mathrm{C}\right)-\mathrm{AuCu}$ II - is an orthorhombic structure. The crystallographic unit cell of $\mathrm{AuCu}$ II, as indicated in Figure 4, may be thought of as consisting of $10 \mathrm{AuCu}$ I tetragonal unit cells placed side by side in the b-direction, with the content of (001) planes changed from all gold atoms to all copper atoms halfway along the new long cell. Thus, the structure is subdivided into domains with adjacent domains being in antiphase. The antiphase domain boundaries are parallel to the [100] direction and have a periodicity of five unit cells along the $\mathrm{b}$-axis. This structure was first deduced by Johansson and Linde from $X$-ray powder diffraction studies (14).

In 1954, Ogawa and Watanabe succeeded in revealing this periodic antiphase domain structure by the electron diffraction technique on evaporated thin films of $\mathrm{AuCu}$ (15). They observed that a splitting of the superlattice reflections and associated satellite reflections appeared on the diffraction patterns, most of which could be adequately explained in terms of the periodic antiphase domain structure postulated by Johansson and Linde. Furthermore, Ogawa and his co-workers, using TEM, were the first to observe the periodic antiphase domain structures in AuCu II (16), Shortly thereafter, Pashley and Presland (17), and Glossop and Pashley (18), reported the existence of two perpendicular orientations of the AuCu II unit cell: one periodic along the a-axis and the other periodic along the b-axis, with a modification of the antiphase boundary configuration through dislocation. The spacing between each of the antiphase boundaries was observed as being approximately $2 \mathrm{~nm}$, in good agreement with previously repotted X-ray diffraction studies.

The effect of additional elements on the period of antiphase domain structure, i.e. on the domain size, is a most interesting question. Ogawa and co-workers showed by direct observation in the electron microscope that the addition of zinc to the AuCu II superlattice reduced the domain size by at least $0.8 \mathrm{~nm}$ (19). The effect of the addition of 16 different elements, in varying concentrations, on the antiphase domain size in $\mathrm{AuCu}$ II was studied by Sato and Toth using electron diffraction techniques (20). They found that the addition of either nickel, palladium, silver or germanium to equiatomic $\mathrm{AuCu}$ caused an increase in domain size of the $\mathrm{AuCu}$ II phase with increasing concentration of the added elements, while additions of aluminium, gallium, indium, tin, manganese and zinc decreased the domain size. These workers also reported that domain size changes in the AuCu II phase were related to the number of valence electrons per atom of the added element. 


\section{Phase Diagram of the Gold-Copper-Silver Ternary System}

Although a knowledge of equilibrium phase diagrams is an important aid in predicting the phase transformations resulting from the ageing of alloys, the ordering regions in the gold-copper-silver ternary system have not yet been established with sufficient accuracy. Stermer-Rainer showed that in the gold-copper-silver phase diagram there is a region where a disordered phase coexists with a gold-copper ordered phase (21). His phase diagram, however, was too sketchy to be used for quantitative description of phase equilibria in this system.

The gold-copper-silver ternary system is characterized by a miscibility gap and a two-phase region in which copper-rich and silver-rich phases coexist. Masing and Kloiber outlined the boundaries of the two-phase region at $673 \mathrm{~K}\left(400^{\circ} \mathrm{C}\right)$ and $987 \mathrm{~K}$ $\left(750^{\circ} \mathrm{C}\right)$ using an $\mathrm{X}$-ray diffraction method $(22)$. Thereafter, $\mathrm{Mc}-$
Mullin and Norton reported the limits of the two-phase region for five different temperatures (23).

In contrast, information on the stable region of AuCu ordering in the ternary system was much more fragmentary. Raub (24) found superlattice reflections in the X-ray diffraction patterns of gold-copper-silver alloys containing up to 30 per cent silver, while Hultgren and Tamopol (24) indicated that the first 5 atomic per cent of silver when substituted for a corresponding amount of gold in the equiatomic gold-copper binary alloy, lowered the critical temperature for ordering by as much as $65 \mathrm{~K}$. They also reported that the ordered AuCu II orthorhombic phase was stable over a wider range of temperature in the gold-copper-silver ternary alloys than in the binary gold-copper alloy. The occurrence of spinodal decomposition was described by Murakami et al. (26).

Although the studies by Hultgren and Tarnopol in 1939, and by Raub in 1949, showed in detail the existing regions and structures of the ordered phases in the gold-copper-silver ternary system, Uzuka, Kanzawa and Yasuda were the first to draw phase boundaries involving ordering in the phase diagram (27). Their experimental results indicated that with increasing silver content, the transformation zone of the AuCu I superlattice in the ternary alloys was pushed towards lower temperatures.

Kikuchi, Sanchez, de Fontaine and Yamauchi calculated a 'coherent' phase diagram for this ternary system, using the interaction energy parameters determined to fit only the binary phase diagrams of gold-copper, copper-silver and silvergold systems (28). Even though it was intended to represent only 'coherent' equilibria (i.e., when all the possible phases differ from each other merely by the arrangement of the constifuent atoms of copper, silvel ol gold on a fixed f.c.c. lattice of the disordered solid solution) the calculated phase diagram
Fig. 5 Isothermal section at $573 \mathrm{~K}\left(300^{\circ} \mathrm{C}\right)$ of Yamauichi's (29) calculated phase diagram of the copper-silver-gold ternary system. $\alpha^{\prime}$ : Alt-rich disordered phase; $\alpha^{\prime}, \alpha^{\prime \prime}$ : Cu-rich disordered phase; $\beta$ : CuzAu-type ordered phase; $\gamma$ AuCu II - type ordered phase; $\delta:$ AuCu I - type ordered phase 
showed striking similarities with the experimentally derived phase diagram of Uzuka et al. (29), as may be seen in Figure 5 . This calculated phase diagram also shows Uzuka's data (designated by the circles and squares), as well as a result of Shashikov and colleagues' observations, which is indicated by an arrowhead (30),

There is no doubt that the phase diagram of the gold-coppersilver ternary system can give very useful information regarding the design of dental gold alloys. However, the data available so far may still be insufficient for a complete definition of the phase diagram.

\section{Application of Transmission Electron Microscopy to Studies of Age-Hardening Mechanisms in Dental Gold Alloys}

TEM has important advantages over other methods of studying the hardening mechanisms in dental gold alloys in that: (i) the results obtained are visual; (ii) it provides high resolution; (iii) additional information about structure and orientation can be obtained by using the selected-area diffraction technique and (iv) the dark field image formed using superlattice reflections readily enables us to distinguish ordered regions from disordered regions, since only the former appears bright.

Notwithstanding these advantages, TEM studies of hardening mechanisms in dental gold alloys are relatively recent.

The earliest TEM study was carried out in 1975 by Kanzawa, Yasuda and Metahi (31) with the object of elucidating the colrelation between microstructure and phase transformations in an 18 carat gold dental alloy, $\mathrm{Au}-35.7 \mathrm{at} . \% \mathrm{Cu}-11.2 \mathrm{at} . \% \mathrm{Ag}$. They found that age-hardening in the alloy is brought about by a twostage process, with initial hardening being due to the formation of coherent $\mathrm{AuCu}$ I ordered platelets, and secondary hardening resulting from twinning, as will be shown later.

Shortly afterwards, Prasad, Eng and Mukherjee studied the age-hardening of a commercial Type III dental gold alloy, using TEM in addition to X-ray diffraction and hardness measurements (32). They reported that hardening was predominantly due to precipitation. The precipitates, which were formed on the $\{100\}$ and $\{111\}$ planes of the matrix, were homogeneously nucleated and coherent with it; ordering also played a role in hardening, but its contribution appeared to be very slight. The above results, however, were not in agreement with those of Yasuda et al. The data may still be insufficient for a definite conclusion to be made as to whether age-hardening in dental gold alloys results from ordering or from precipitation.

As can be seen in Figure 5, the gold-copper-silyer ternary system is characterized by ordering regions and a two-phase decomposition region in which copper-rich and silver-rich phases coexist. If the alloy has a composition falling in the ordering region, age-hardening will be due to an order-disorder transformation mechanism. On the other hand, if the alloy is located in the two-phase region, precipitation hardening will
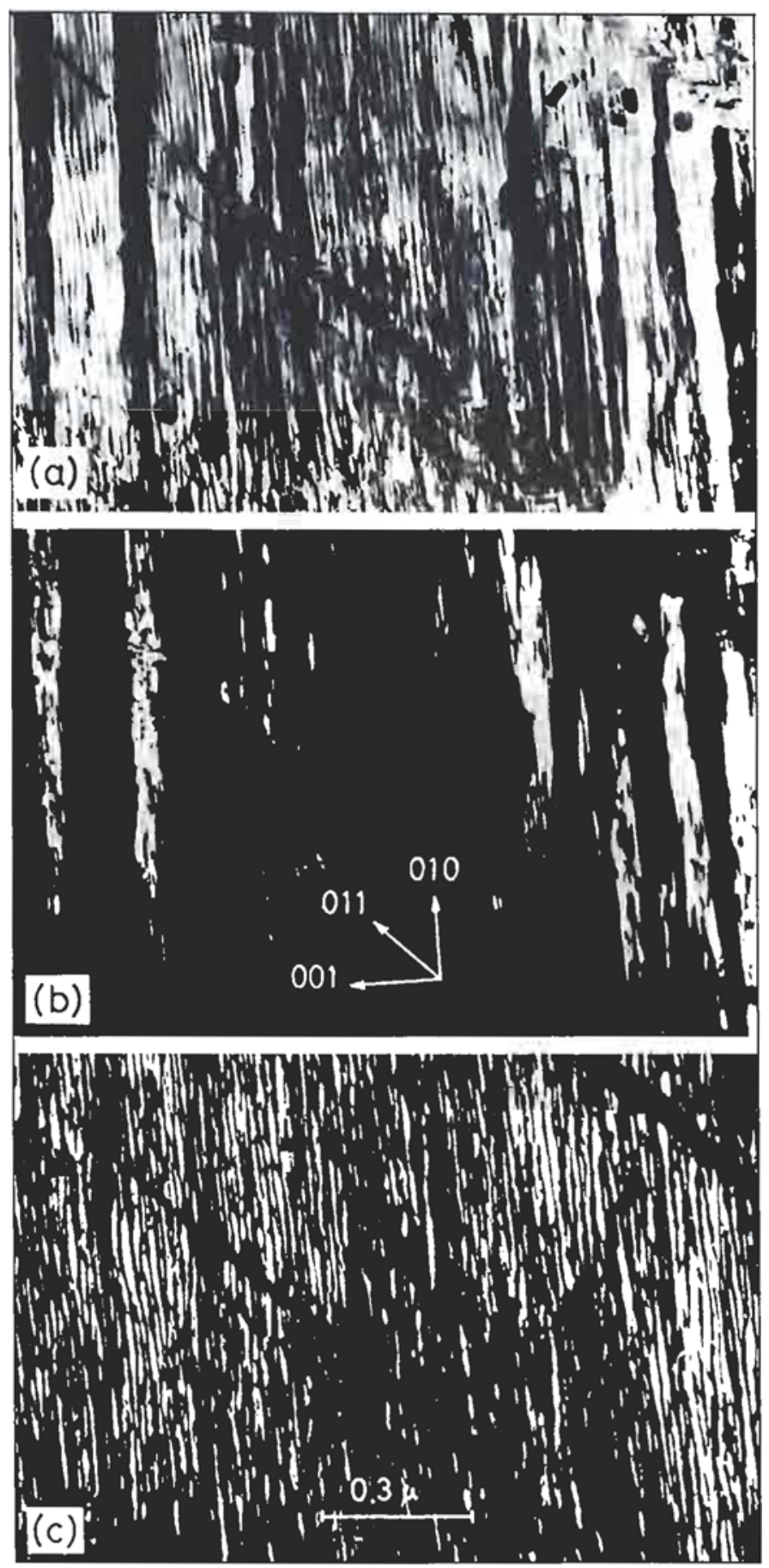

Fig. 6 Electron micrographs showing the stepwise arrangement of $\mathrm{AuCu}$ I superlattice platelets formed in the 18 carat alloy by ageing at $573 \mathrm{~K}$ $\left(300^{\circ} \mathrm{C}\right)$ for $4.3 \times 10^{2} \mathrm{ks}(120 \mathrm{hr})$. a). Bright field image: the incident electron beam was nearly parallel to the [100] direction. b). and c). Dark field images formed by using the 110 and 001 superlattice reflections respectively

occur.

It is supposed that the age-hardening characteristics of these alloys are affected by their composition, especially by the 
atomic ratio of gold to copper. Because the tendency for twophase decomposition may markedly increase with decreasing gold content, the effect of the ordered phase on hardening may diminish or disappear altogether. However, it has not been clearly demonstrated that a difference in the age-hardening mechanism of temary dental gold-copper-silver alloys occurs with changes in gold content. Therefore, Yasuda and his coworkers conducted studies to elucidate the differences in har- dening mechanisms for 18,16 and 14 carat gold alloys, in which the ratio of copper to silver was maintained between at $65: 35$ by weight, using electron diffraction and TEM in addition to Xray diffraction, electrical resistivity measurements and hardness tests.

The 18 carat Alloy. Their experimental results for the 18 carat alloy, published in 1975 (31), showed that age-hardening was due to the formation of platelets of AuCu I superlattice on

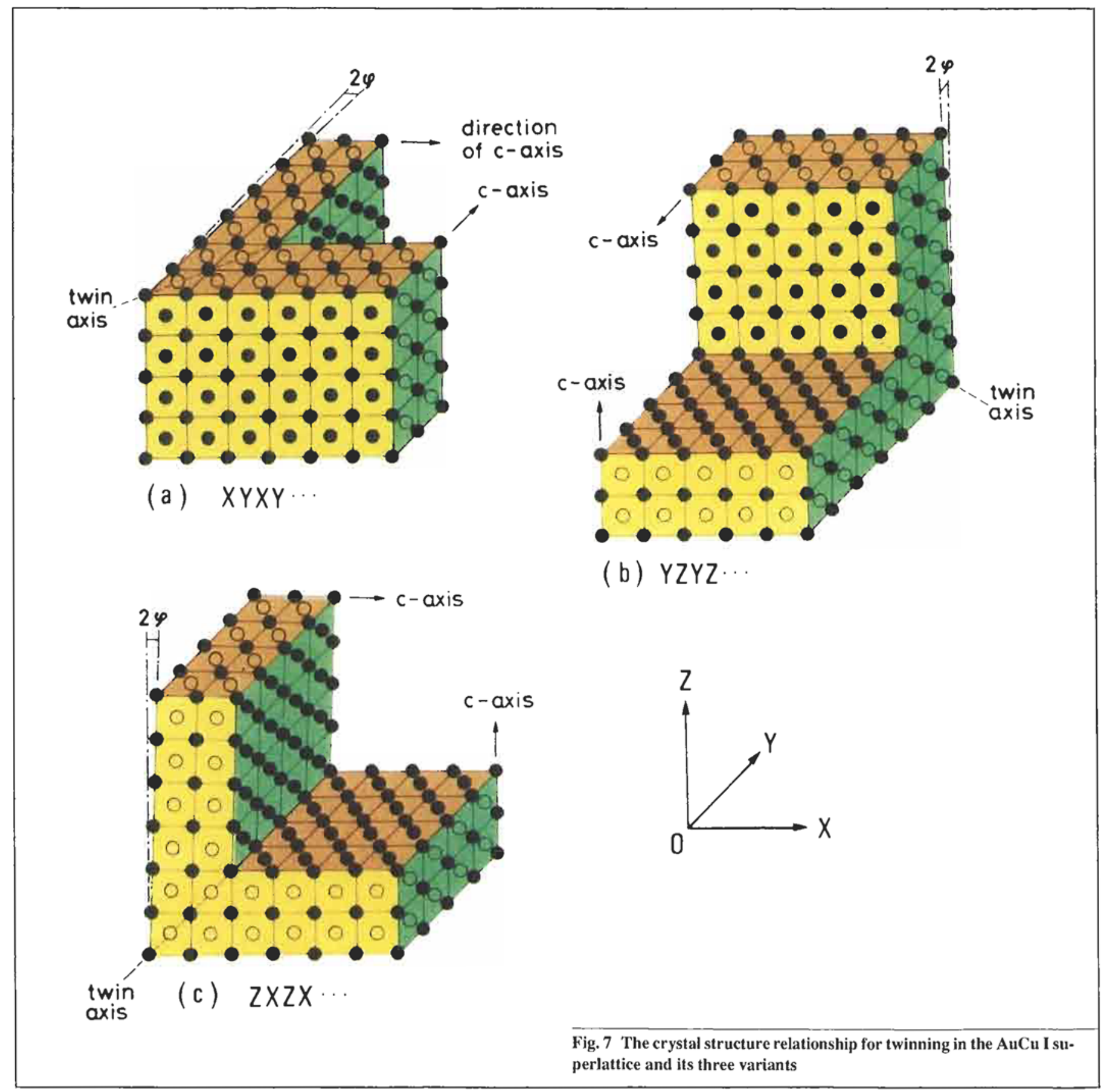




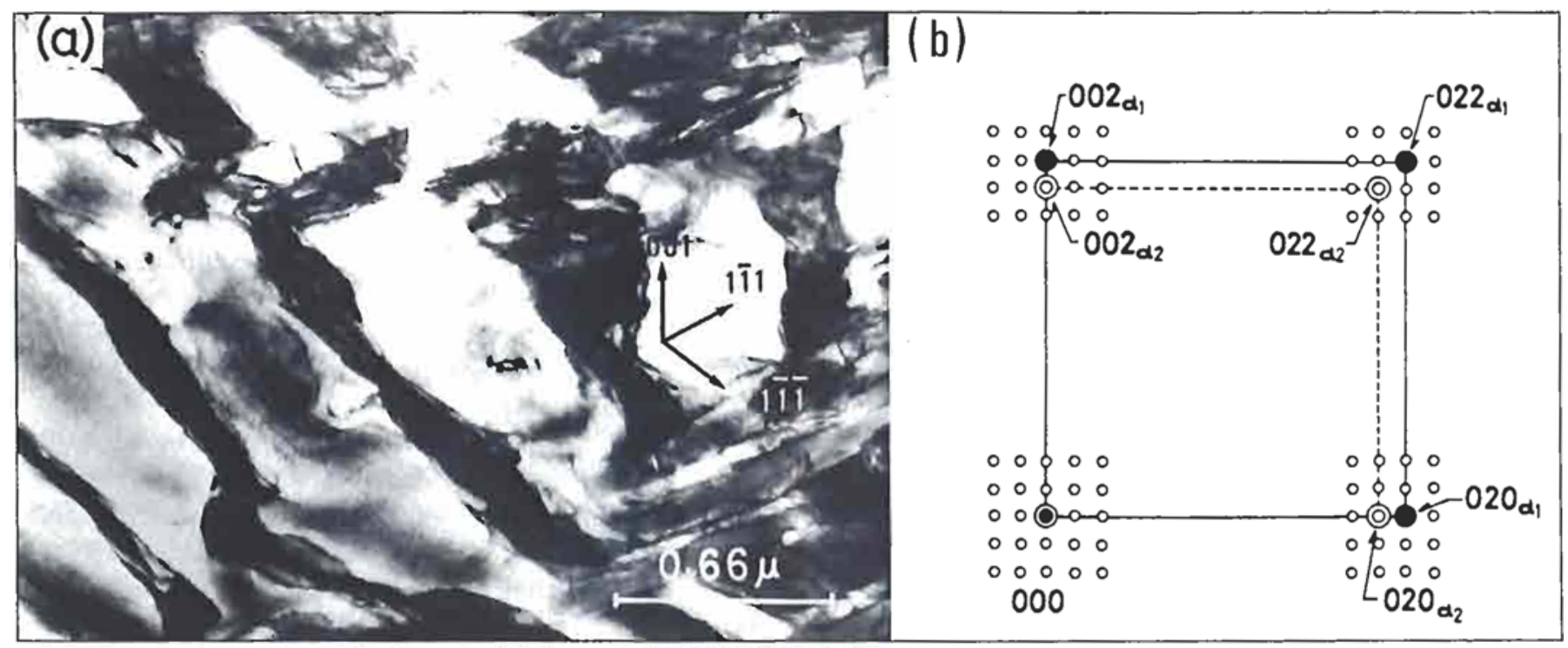

Fig. 8 Bright field image (a) of the 16 carat gold alloy aged at $723 \mathrm{~K}$ for $72 \mathrm{ks}(20 \mathrm{hr})$, and (b) a schematic representation of its electron diffraction pattern. The large solid circles indicate the $\alpha_{1}$ phase, the double circles the $\alpha_{2}$ phase and the small open circles the extra reflections which are due to the double diffraction effect

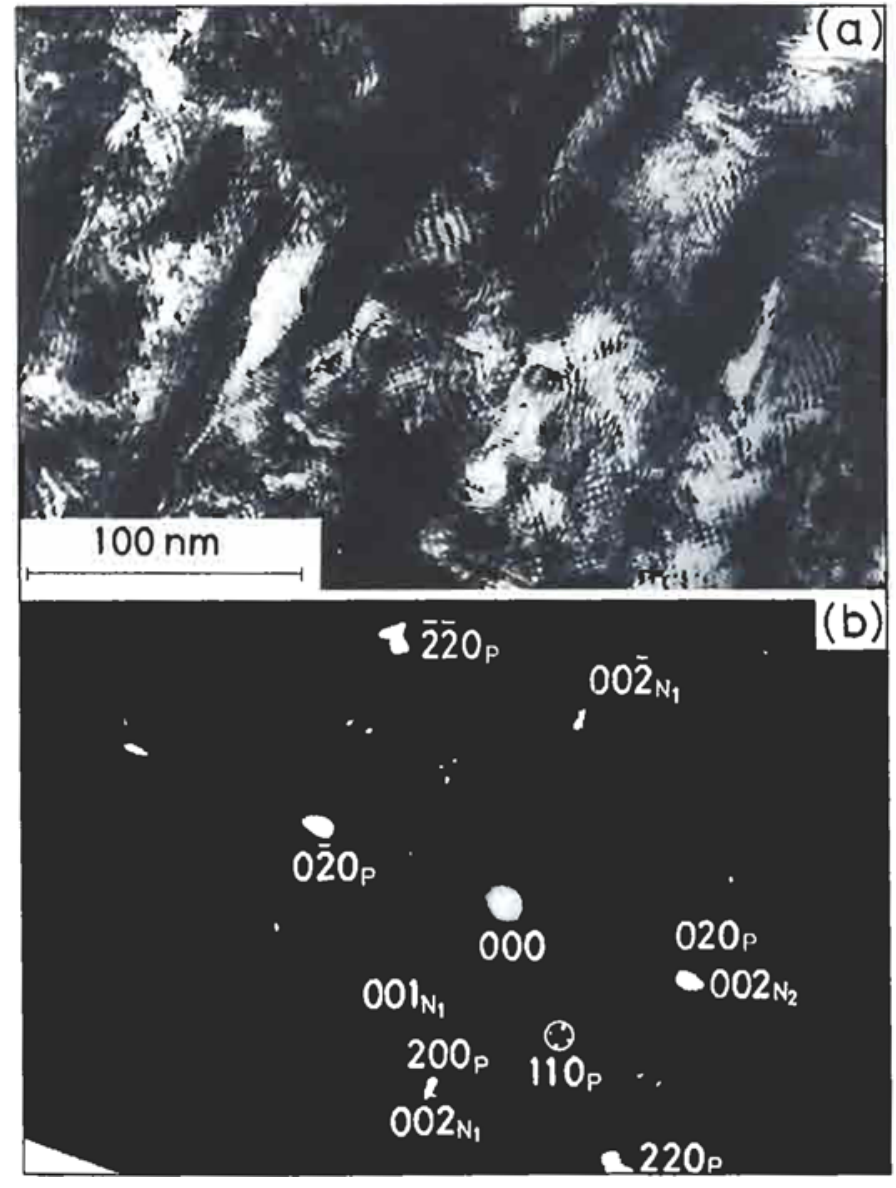

Fig. 9 Dark field image (a) and selected-area electron diffraction pattern (b) of the 14 carat gold alloy aged at $543 \mathrm{~K}\left(270^{\circ} \mathrm{C}\right)$ for $7.2 \times 10^{2} \mathrm{ks}(200 \mathrm{hr})$. The diffraction spot enclosed by the circle in (b) was used to form the dark field image

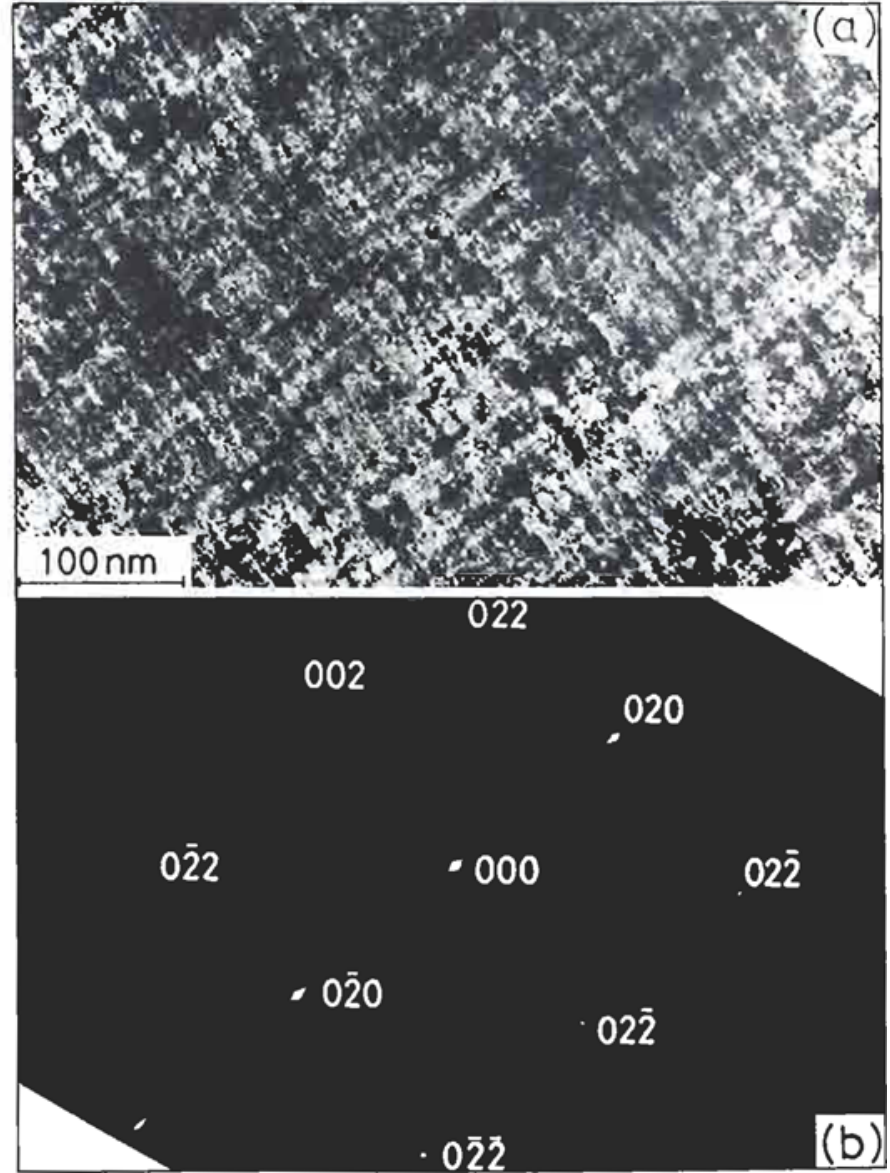

Fig. 10 An electron micrograph and selected-area electron diffraction pattern of the 14 carat gold alloy after ageing at $673 \mathrm{~K}\left(400^{\circ} \mathrm{C}\right)$ for $60 \mathrm{~s}$.

(a) is a bright field image and (b) is an electron diffraction pattern corresponding to (a) 
the matrix $\{100\}$ planes. As shown in Figure 6, these ordered platelets are arranged in a stepwise fashion that roughly follows $\mathrm{d}_{\text {dis }}$ traces on the $\{100\}$ planes, and theil c-axes are distributed in the three cube edge directions of the parent disordered matrix (Figure 7). Thus, it was observed that at a later stage of ageing, twinning took place on the (101) tet plane to relieve a considerable amount of strain induced in the matrix through changes in crystal symmetry.

The 16 carat Alloy. On the other hand, at the lower ageing temperatures, age-hardening in the 16 carat gold dental alloy, $\mathrm{Au}-43.2 \mathrm{at} . \% \mathrm{Cu}-13.8 \mathrm{at} . \% \mathrm{Ag}$, was found to be due to the development of a long-period antiphase domain structure in the AuCu II superlattice (33). The unidirectional, alternating fine lamellar structure, consisting of the $\mathrm{AuCu} I$ superlattice, was also found to be present in several different areas of the same specimen. The hardening effect was thought to be the result of increased lattice strain induced by the structural changes.

In a higher temperature range, an alternating coarse lamellar structure, consisting of a f.c.c. lattice of copper-rich $\alpha_{1}$ and sil- ver-rich $\alpha_{2}$ phases, was formed by discontinuous decomposition. These two phases are orientated parallel to each other (Figure 8). No age-hardening was observed in this temperature range.

However, considerable age-hardening was found to occur in the middle temperature range, in spite of the similarity between the microstructures after ageing at these temperatures and at higher ones. In this respect, it was thought that the ordering and the decomposition of supersaturated solid solution took place simultaneously during the ageing process in this temperature range.

The 14 carat Alloy. In the 14 carat gold alloy studied by Yasuda et al. (Au-49.7at.\%Cu-15.8at.\%Ag), which possessed an off-stoichiometric composition of $\mathrm{AuCu}$, it was expected that age-hardening would also proceed from disordered solid solution by $\mathrm{AuCu}$ ordering accompanied by the two-phase decomposition (34). The microstructure of this alloy at the lower ageing temperature range showed a fine mottled contrast parallel to the $d$ directions in the early stages of ageing. This fine con-

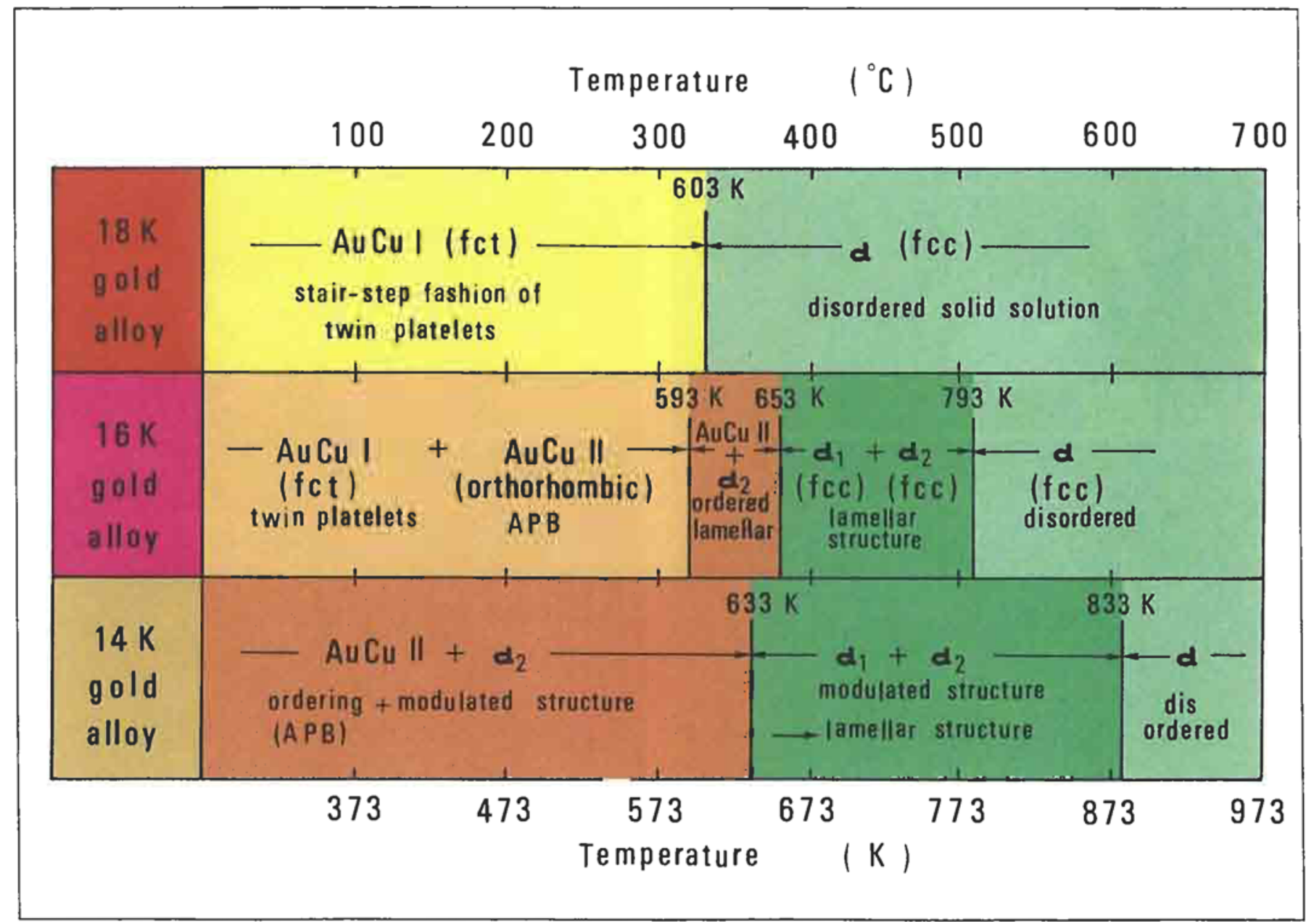

Fig. 11 A schematic representation of age-hardening mechanisms and the associated microstructures in the 18,16 and 14 carat ternary gold alloys 
trast was due to the formation of a modulated structure induced by spinodal decomposition, which was confirmed by the appearance of side-bands in X-ray diffraction patterns and satellite reflections in electron diffraction patterns. With longer ageing periods, the modulated structure changed to a 'tweedlike' structure consisting of copper-rich $\alpha_{1}$ and silver-rich $\alpha_{2}$ phases. The $\alpha_{1}$ phase gradually transformed to the long-period superlattice $\mathrm{AuCu}$ II (Figure 4) through the introduction of gold atoms from the alloy matrix into the $\alpha_{I}$ phase.

Figure $9 \mathrm{a}$ shows the dark field image formed by using the 110 superlattice reflection in this ageing stage. Figure $9 \mathrm{~b}$ is the corresponding selected area electron diffraction pattern taken from the central part of Figure 9a. Cross-like splitting at the 110 and equivalent superlattice reflection positions indicate alignment of the antiphase domains in orthogonal directions, as there are two equivalent b-directions with a common c-axis.

In the higher ageing temperature range, a bright field electron micrograph showed a large number of alternating dark and bright striations (Figure 10a). These striations run parallel to the $\mathrm{d}$ directions and are arranged almost at right angles to each other. As can be seen in Figure 10b, satellite reflections are present in the selected-area electron diffraction pattern taken from the central region of Figure 10a. The appearance of the striations suggested the presence of periodic variations of the lattice parameter and in the atomic scattering factor, caused by the periodic composition fluctuation along $d$, i.e. the formation of a modulated structure.

The structural and morphological changes which give rise to age-hardening in the 18,16 and 14 carat alloys are summarized and collated in Figure 11. In the figure, hatched bands indicate the temperature at which the hardness peak appears (35).

Effect of Silver Content. The effect of changes in silver content on the age-hardening mechanism $\mathrm{AuCu}-\mathrm{Ag}$ pseudo-binary alloys was also studied by means of hardness tests, $\mathrm{X}$-ray and electron diffraction and TEM (36). Hardening in a low silvercontent alloy, AuCu-6at.\%Ag, aged at $573 \mathrm{~K}\left(300^{\circ} \mathrm{C}\right)$ was found to be due to the formation of $\mathrm{AuCu}$ I platelets formed along $\mathrm{n}$ directions of the matrix and the consequent increase in the elastic strain field. Growth of the ordered platelets caused twinning, which resulted in a softening of the alloy by releasing the elastic strain. The twinning of the AuCu I ordered phase was suppressed by the addition of more silver to the alloy.

The long-period antiphase domain configuration was also observed in the specimen aged at $603 \mathrm{~K}\left(330^{\circ} \mathrm{C}\right)(37)$. Figure $12 \mathrm{a}$ shows the dark field image formed using the $110_{\mathrm{z}}$ superlattice reflection. Figures $12 \mathrm{~b}$ and $12 \mathrm{c}$ show respectively the corresponding selected-area electron diffraction pattern and its schematic representation. It can be seen that a large number of the fringes abut on each other at an angle which slightly deviates from a right angle, as was reported by Watanabe and Takashima (38). The wavy character of the antiphase domain boundaries was demonstrated by high resolution TEM observation of the

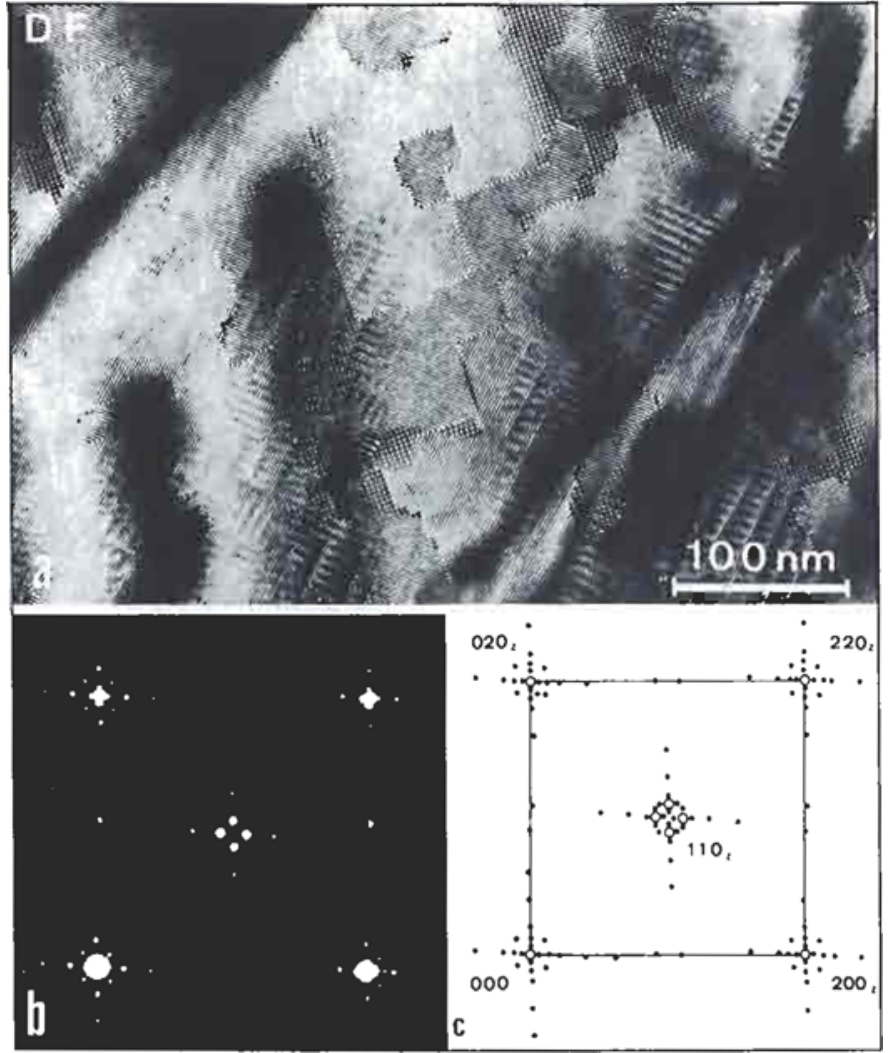

Fig. 12 Dark field TEM micrograph and electron diffraction pattern of the $\mathrm{AuCu}-6 \mathrm{at} . \% \mathrm{Ag}$ alloy after ageing at $613 \mathrm{~K}\left(340^{\circ} \mathrm{C}\right)$ for $100 \mathrm{ks.}$ a). Dark field image formed using the $110 z$ superlattice reflection. b). \& c). The corresponding electron diffraction pattern and its schematic representation

$\mathrm{AuCu}-6 \mathrm{at} . \% \mathrm{Ag}$ alloy (39).

In contrast, age-hardening in the high silver-content alloys was attributed to the dual mechanisms of phase separation and ordering. In the $\mathrm{AuCu}-31.1$ at.\% Ag alloy, for example, aged at $573 \mathrm{~K}\left(300^{\circ} \mathrm{C}\right)$, phase separation was thought to proceed by spinodal decomposition, followed by the formation of a modulated structure of increasing periodicity which grows into a characteristic block-like structure consisting of alternating ordered $\mathrm{AuCu}$ II orthorhombic phase and silver-rich $\alpha_{2}$ phase. In the initial stages of ageing, most of the hardening was caused by the development of the modulated structure. The hardening that occurred upon further ageing was attributed to ordering in the copper-rich $\alpha_{1}$ phase.

\section{Age-Hardening Mechanisms in Gold-Copper-Silver-Palladium Quaternary Alloys and Commercial Dental Golds}

Since the investigations of Wise et al. concerning quaternary gold alloys $(6,7)$, it has been known that the addition of palladium and/or platinum to ternary gold-copper-silver alloys gives rise to conspicuous age-hardening characteristics. To clarify the crystallography and morphology of the hardening 
phase in these alloys, Yasuda and Kanzawa (39) carried out TEM studies on a quaternary gold alloy, Au-35.4at.\%Cu17.8 at. \% Ag-9.7at.\%Pd, which was prepared so as to contain the equivalent of 2 carats of palladium substituted for a corresponding amount of gold in a 16 carat gold-copper-silver alloy.

The results obtained were as follows. The age-hardening observed in this quaternary alloy was due to the formation of $\mathrm{AuCu} I$ ordered nuclei on the disordered matrix $\{100\}$ planes. In adjacent ordered platelets of $\mathrm{AuCu}$ I, the c-axes were mutually perpendicular to compensate for the strain induced by their tetragonality, as was also observed in the 18 carat ternary alloy (31). To relieve the strain caused by the tetragonal distortion in the ordered domains, twinning took place on the (101)tet plane at a later stage of ageing in the way shown in Figures 6 and 7. The nodular precipitates that also formed at grain boundaries did not play an important role in age-hardening. Thus, it became clear that the hardening mechanism observed in the quaternary gold alloy was analogous to that previously found in the 18 carat gold ternary alloy.

Although the hardening mechanism in dental gold alloys was thought to be attributable to a coherency strain field at the interface between the AuCu I ordered platelets and the surrounding matrix, the configuration of the interface, which could provide direct evidence of the presence of a coherency strain

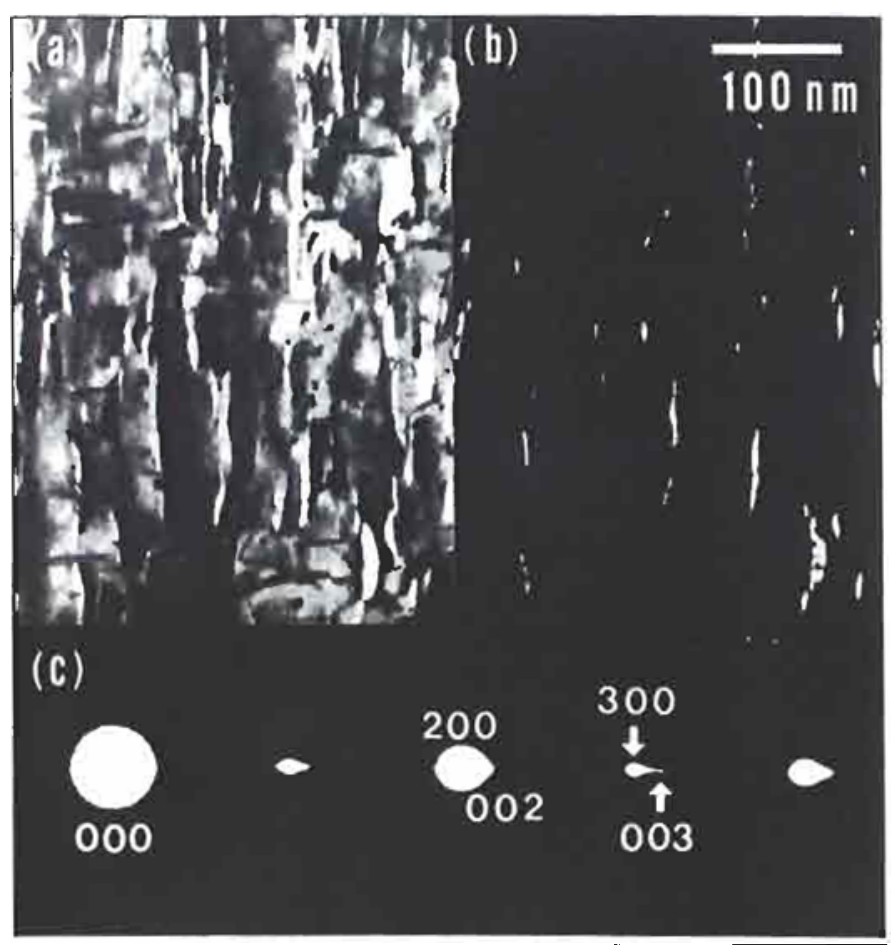

Fig. 13 Dark field TEM micrographs and an enlargement of the electron diffraction pattern of a commercial 18 carat gold dental alloy aged at 573K $\left(300^{\circ} \mathrm{C}\right)$ for $1.8 \times 10^{3} \mathrm{ks}(500 \mathrm{hr})$. a). and b). Dark field images formed using the 300 and 003 superlattice reflections, respectively. c). The enlarged diffraction pattern corresponding to (a) and (b) field, could not be deduced by conventional TEM. High resolution TEM coupled with electron diffraction, however, provided direct information on crystal structures down to the scale of interatomic distances, and proved to be extremely effective for elucidating the structural characteristics of interfaces between different phase under suitable imaging conditions. These techniques were therefore employed for studying the strain fields generated at the interface between the $\mathrm{AuCu} \mathrm{I}$ and $\mathrm{Au} 3 \mathrm{Cu}$ ordered phases in the $18 \mathrm{~K}-\mathrm{S}$ commercial dental gold alloy (44).

Commercial palladium-containing dental gold alloys were also studied to elucidate their hardening mechanisms and associated phase transformations, since it was expected that the age-hardening mechanism varied greatly depending on the composition of the alloy (41). The two alloys studied were Au26.5at.\%Cu-18.2at.\%Ag-7.9at.\%Pd (16K-S) and $\mathrm{Au}-$ 25.3 at.\%Cu-27.4at.\%Ag-7.6at.\%Pd (14K-S). In these alloys, two stages of ordering could be distinguished by TEM and electron diffraction studies of isochronal ageing of a supersaturated solid solution. In the first stage, ordering of a metastable $\mathrm{AuCu} \mathrm{I}^{\prime}$ superlattice occurred as a stepwise arrangement of platelets situated on the $\{100\}$ planes. This structural feature was also analogous to that found in the 18 carat gold ternary alloy (31). Prolongation of the ageing period caused the formation of a lamellar structure consisting of the equilibrium AuCu I ordered phase and the silver-rich $\alpha_{2}$ phase. The metastable $\mathrm{AuCu} \mathrm{I}^{\prime}$ ordered platelets were formed prior to the ordered equilibrium AuCu I phase. Platelet formation was accompanied, in the $16 \mathrm{~K}-\mathrm{S}$ alloy, by a contraction of about 7 per cent in the surrounding matrix in a direction normal to the plane of the $\mathrm{AuCu} \mathrm{I}^{\prime}$ ordered platelets, i.e., this direction coincided with the $\mathrm{C}$-axis of the $\mathrm{AuCu} \mathrm{I}^{\prime}$ ordered phase. In the $14 \mathrm{~K}-\mathrm{S}$ alloy, the contraction was about 6 per cent. The strain introduced by the tetragonality of the AuCu I' structure led to substantial hardening in the early stages of ageing.

Isothermal age-hardening curves for the two alloys showed that, after a rapid increase in the early stages of ageing, the hardness dropped drastically as ageing was prolonged (42). This marked decrease in hardness, (over-ageing), was due to the formation, by a heterogenous mechanism, of the equilibrium $\mathrm{AuCu}$ I ordered phase and of the $\alpha_{2}$ phase at grain boundaries as a lamellar structure. It was thought that, during lengthy ageing, these lamellae would continue to grow at the expense of the metastable AuCu I' ordered platelets formed inside the grains. The strain field generated by the formation of the $\mathrm{AuCu} \mathrm{I}^{\prime}$ ordered platelets was therefore relieved as a result of the growth of the lamellar structure. Thus, loss of coherency at the interface between the ordered platelets and the matrix caused the hardeness to decrease.

Recently, a different type of age-hardening mechanism has been found to occur upon appropriate heat treatment in a commercial 18 carat gold dental alloy, $\mathrm{Au}-31.7$ at. $\% \mathrm{Cu}-8.1 \% \mathrm{Pd}$ 5.3at.\% Ag (18K-S) (43). X-ray and electron diffraction studies 
as well as TEM showed that a $\mathrm{Au}_{3} \mathrm{Cu} \mathrm{L}_{2}$ type f.c.c. superlattice and a disordered f.c.c. phase were formed by ageing at $673 \mathrm{~K}$ $\left(400^{\circ} \mathrm{C}\right)$. Hardening occurred through the mechanism of the antiphase domain-size effect. The $\mathrm{Ll}_{0}$ type $\mathrm{AuCu}$ I superlattice was also formed in regions adjacent to the $\mathrm{Au}_{3} \mathrm{Cu}$ ordered phase in the later stages of ageing below $623 \mathrm{~K}\left(350^{\circ} \mathrm{C}\right)$, as shown in Figure $13 \mathrm{a}, \mathrm{b}$ and $\mathrm{c}$. In the micrographs, $\mathrm{a}$ and $\mathrm{b}$ show dark field images taken using the 300 superlattice reflection for the $\mathrm{Au} 3 \mathrm{Cu}$ phase and the 003 superlattice reflection for the $\mathrm{AuCu}$ I ordered phase, and $c$ is the enlarged diffraction pattern corresponding to $\mathrm{a}$ and $\mathrm{b}$. From the micrographs, it is clear that the $\mathrm{AuCu} \mathrm{I}$ ordered platelets are formed in the $\mathrm{Au}_{3} \mathrm{Cu}$ ordered domains along $\mathrm{d}$ directions. Thus, it was concluded that the hardening should be attributed not only to the antiphase domain-size effect, but also to the elastic strain field induced by the formation of the ordered $\mathrm{AuCu} 1$ platelets in the ageing temperature range below $623 \mathrm{~K}\left(350^{\circ} \mathrm{C}\right)$.

Although the hardening mechanism in dental gold alloys was thought to be attributable to a coherency strain field at the interface between the $\mathrm{AuCu} I$ ordered platelets and the surrounding matrix, the configuration of the interface, which could provide direct evidence of the presence of a coherency strain field, could not be deduced by conventional TEM. High resolution TEM coupled with electron diffraction, however; provided direct information on crystal structures down to the scale of interatomic distances, and proved to be extremely effective for elucidating the structural characteristics of interfaces between different phase under suitable imaging conditions. These techniques were therefore employed for studying the strain fields generated at the interface between the $\mathrm{AuCu} \mathrm{I}$ and $\mathrm{Au}_{3} \mathrm{Cu}$ ordered phases in the $18 \mathrm{~K}-\mathrm{S}$ commercial dental gold alloy (44).

Figure 14 shows the dark field image taken from the

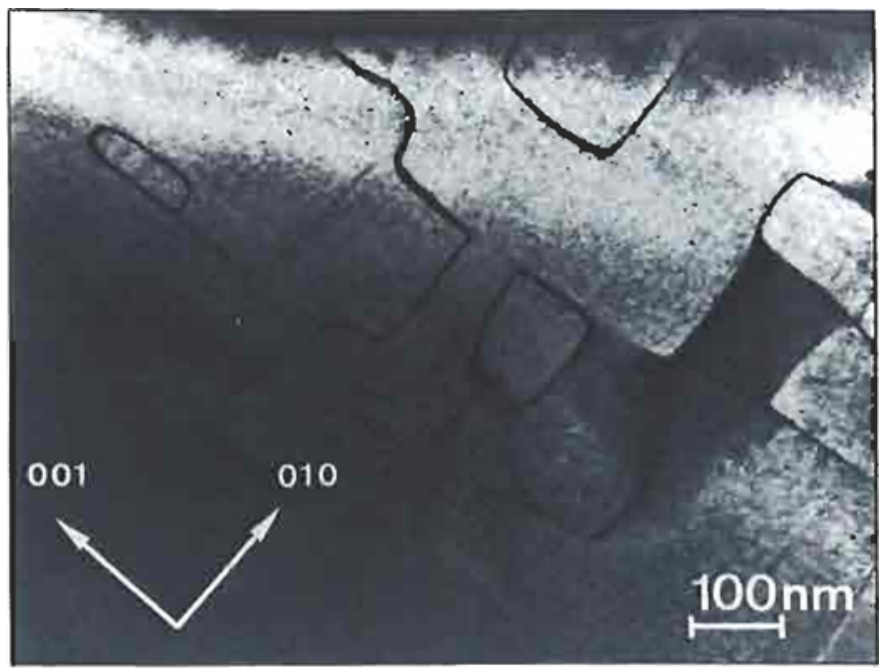

Fig. 14 Dark field image of a commercial 18 carat gold dental alloy aged at $673 \mathrm{~K}\left(400^{\circ} \mathrm{C}\right)$ for $1.8 \mathrm{Ms}$, taken by conventional electron microscopy using the 110 superlattice reflection

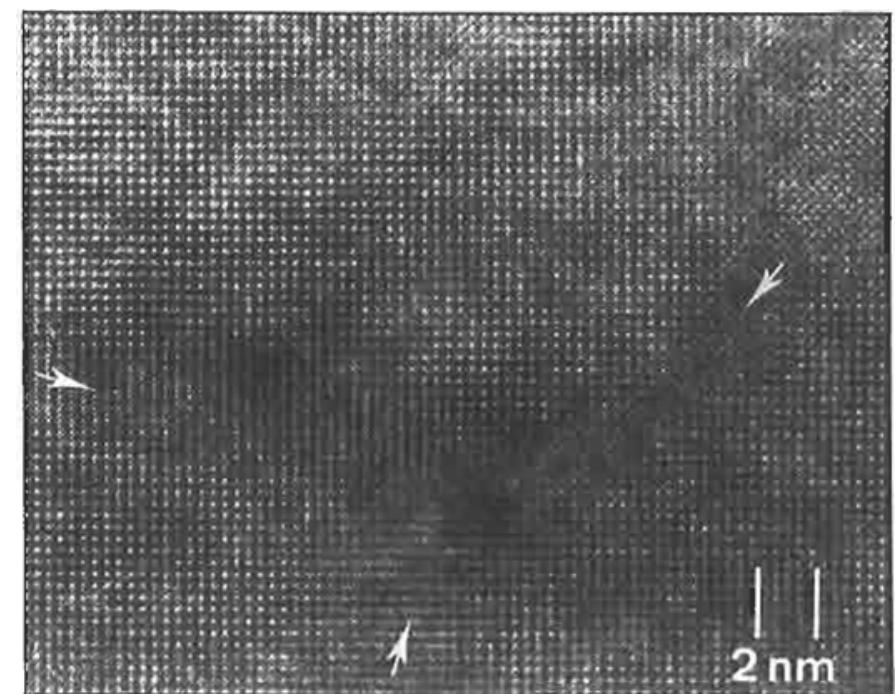

Fig. 15 High resolution TEM micrograph along the [100] direction of the Au3 $\mathrm{Cu}$ superlattice. A triple junction of antiphase domain boundaries (indicated by arrows) is observed. The separation of the bright dots, which represent copper atoms, is $0.4 \mathrm{~nm}$

specimen aged at $673 \mathrm{~K}\left(400^{\circ} \mathrm{C}\right)$ for $1.8 \mathrm{Ms}$ by using an $110 \mathrm{su}-$ perlattice reflection, with the incident electron beam parallel to the [100] direction, using conventional electron microscopy techniques. In the micrograph, the dark stripes which run approximately parallel to the d directions are antiphase domain boundaries that contribute to the hardening of the alloy. However, the atomic arrangement at the antiphase domain boundary could not be found in the micrographs obtained by the conventional dark field imaging technique.

Figure 15 is a high resolution image taken from the same region of the crystal as in Figure 14. The square pattern of bright dots has the same configuration and scale as the projection of the copper columns in the $\mathrm{Au}_{3} \mathrm{Cu}$ ordered structure. This configuration is shown schematically in Figure 16a, and is clearly evident that the copper columns are at the correct positions with respect to the basic f.c.c. lattice, i.e. at each corner of the square. A shift in the arrays of the bright dots occurs across the interfaces, i.e. at the antiphase domain boundaries as indicated by the arrows in Figure 15. This configuration will be readily understood in terms of the schematic representation shown in Figure 16b. The presence of antiphase domain boundaries introduces a local change in chemical composition, i.e. excess atoms with respect to the stoichiometric composition are segregated along the antiphase domain boundaries, as discussed by Van Tendeloo and Amelinckx (45). Thus, it was thought that this segregation contributed to the hardening as well as to the higher energy at the antiphase domain boundaries.

When ageing was carried out below $623 \mathrm{~K}\left(350^{\circ} \mathrm{C}\right)$, the $\mathrm{AuCu}$ I ordered platelet was formed in regions adjacent to the $\mathrm{Au}_{3} \mathrm{Cu}$ ordered matrix (Figure 13).

Figure $17 \mathrm{a}$ is a bright field high resolution image produced 


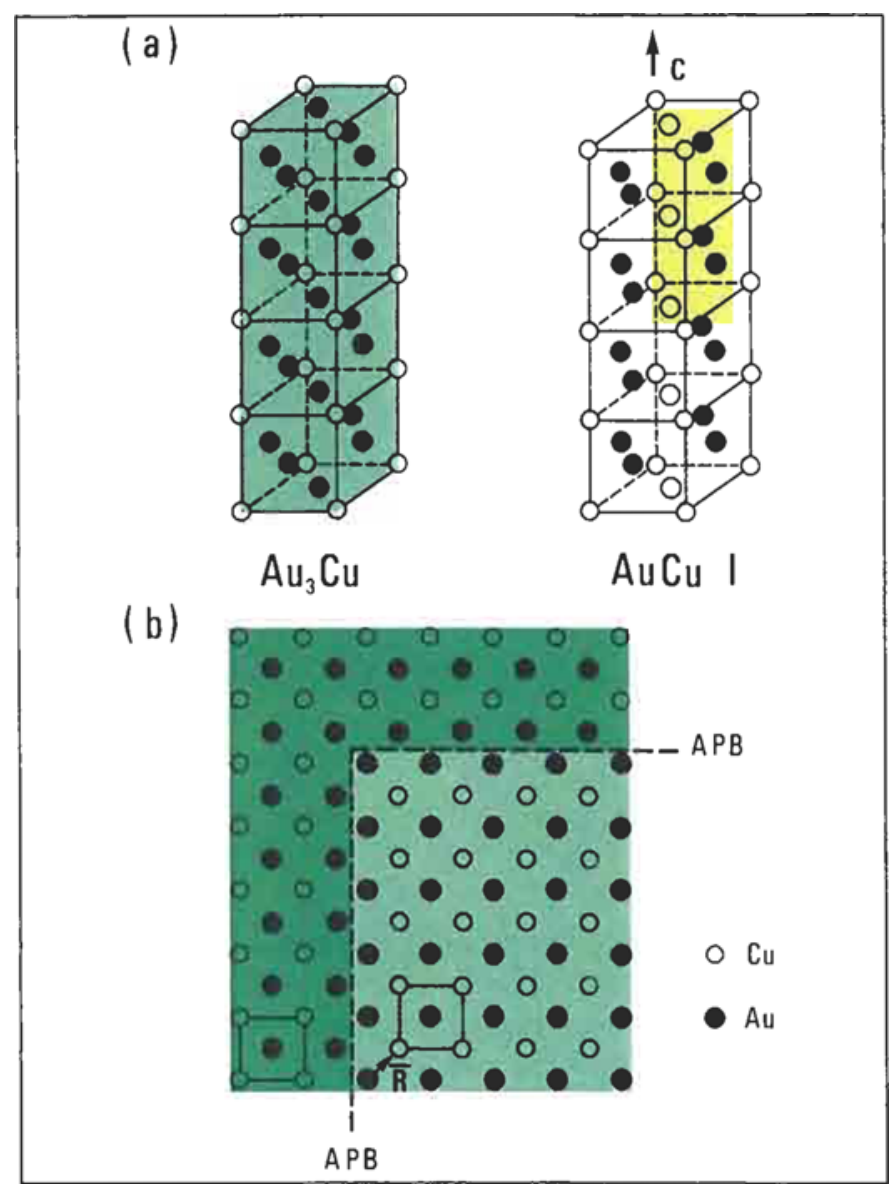

Fig. 16 a). Schematic representation of 4 unit cells of the $\mathrm{Au}_{3} \mathrm{Cu}$ superlattice (left) and $\mathrm{AuCuI}$ superlattice (right). The c:a ratio in $\mathrm{AuCu} I$ has been drawn to scale. b). [001] projection of a single antiphase domain boundary ( $\mathrm{APB}$ ) in $\mathrm{Au}_{3} \mathrm{Cu}$. Only one plane has been drawn; the next plane contains gold atouns only and is continuous across the boundary

using the $001,100,110$ and equivalent superlattice reflections, the fundamental reflections being excluded, and contains an interface between a AuCu I ordered platelet and the ordered Aus $\mathrm{Cu}$ matrix. (In the micrograph, the direction of the c-axis of the $\mathrm{AuCu}$ I ordered platelet is indicated by an arrow, while the arrowhead points to an antiphase domain boundary.)

Figure $17 \mathrm{~b}$ is also a high-resolution image which shows in detail the arrangement of the columns of atoms along the interface between the $\mathrm{AuCu} \mathrm{I}$ and $\mathrm{Au}_{3} \mathrm{Cu}$ ordered phases. In spite of the disturbance caused by the presence of strain and strain contrast, the interface is clearly visible owing to the small difference in interatomic distance between the $\mathrm{AuCu}$ I and $\mathrm{Au} 3 \mathrm{Cu}$ phases. These phases were further indentified from optical diffraction patterns. In Figure 17a, it can be seen that the amount of elastic strain increases with the thickness of the AuCu I ordered platelet (i.e. the length along the $c$-direction within the limited range of the elastic limit). The width, or thickness, of the $\mathrm{AuCu}$ I platelet image is certainly limited by the strain contrast associated with the difference in lattice parameters along the c-axis for $\mathrm{AuCu} \mathrm{I}$ and $\mathrm{Au}_{3} \mathrm{Cu}$. If, as shown schematically in Figure 18, it is assumed that at the top of such a platelet, the pure copper (001) planes in AuCu I coincide with the mixed gold-copper planes in $\mathrm{Au}_{3} \mathrm{Cu}$, then with an axial c/a ratio of 0.90 for a platelet with a half-width of $5 \mathrm{AuCu} I$ unit cells, the pure copper planes will now coincide with the pure gold planes. For a c/a ratio of 0.945 , which was the measured value from the diffraction patterns, the width of the AuCu I platelet will be 18 or 19 units thick. This explanation is in good agreement with the experimental observations; indeed, such a mismatch of the antiphase domain boundary is observed in Figure 17a. Thus, it was concluded that the $\mathrm{AuCu}$ I ordered platelets, being coherent with the $\mathrm{Au}_{3} \mathrm{Cu}$ ordered phase as matrix, gave rise to considerable amounts of elastic strain which could be a major contribution to the age-hardening of the alloy.
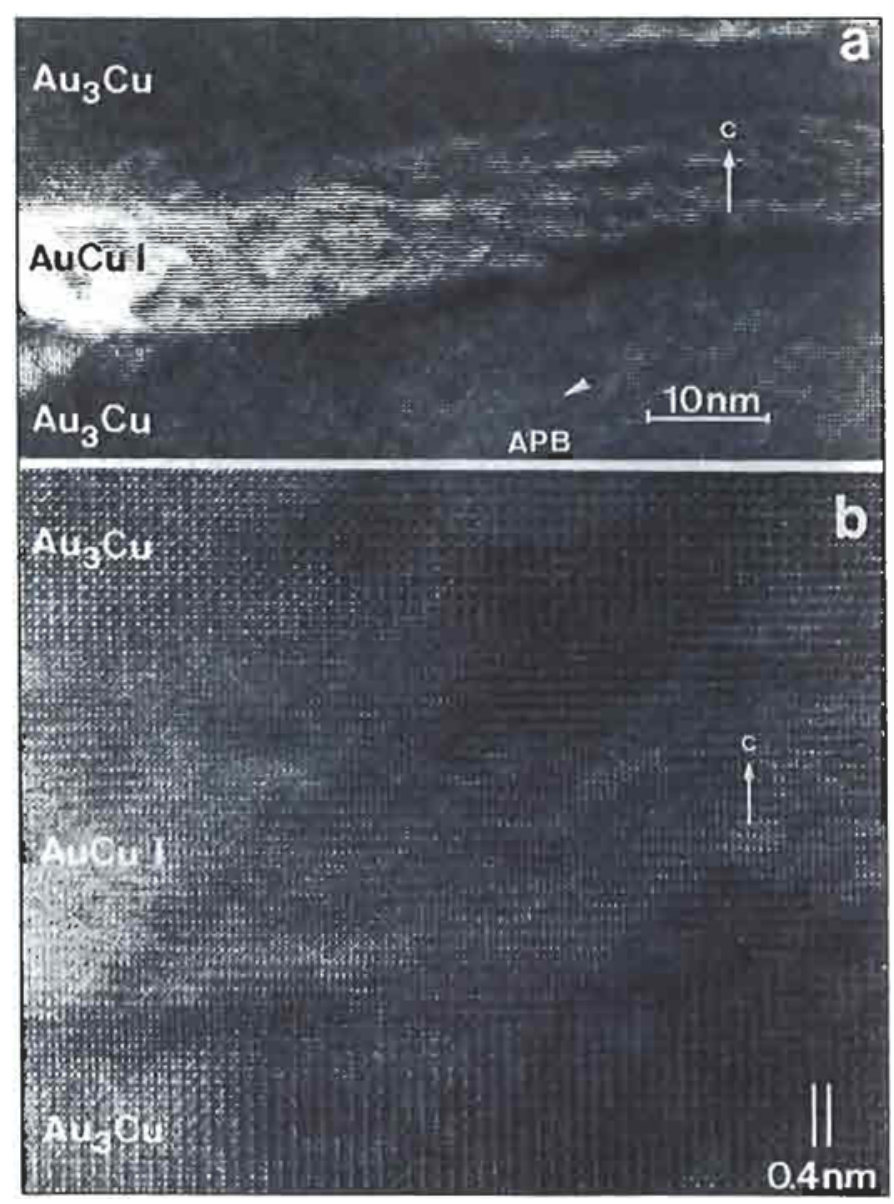

Fig. 17 Bright field high resolution TEM innages of a commercial 18 carat gold dental alloy aged at $573 \mathrm{~K}\left(300^{\circ} \mathrm{C}\right)$ for $1.8 \mathrm{Ms}$.

a). Only the superlattice reflections were selected for imaging.

b). All reflections up to $220_{\mathrm{fcc}}$ were selected for imaging 


\section{Conclusion}

This review article has attempted to show that TEM is a powerful tool for studying age-hardening mechanisms in dental gold alloys. In particular, high resolution TEM coupled with electron diffraction are extremely effective in helping to elucidate the structural changes, down to the scale of interatomic distances, that are associated with a phase transformation during age-hardening, even though the results are still mainly of a qualitative nature. The author hopes that this article will provide future researchers in this field with a better understanding of the need for fundamental studies, which will ultimately result in a more effective utilization of dental alloys for the best patient care.

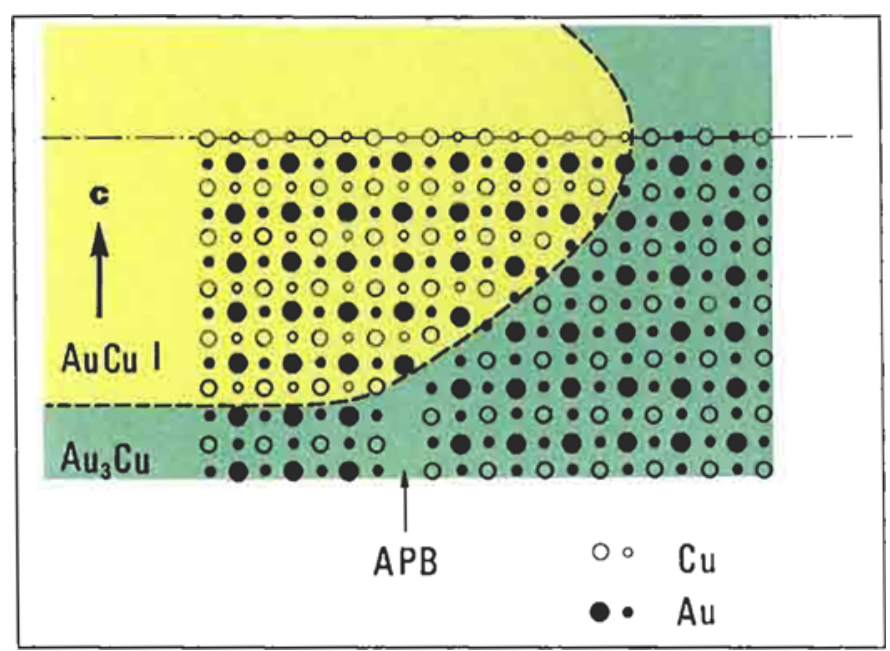

Fig. 18 Schematic representation of a $\mathrm{AuCu}$ I platelet in an $\mathrm{Au}_{3} \mathrm{Cu}$ matrix for a c/a ratio of 0.9 . An antiphase domain boundary (ABP) is generated automatically if copper continuity is required along the centre of the platelet. Large circles are at level 0 ; small circles are at level $1 / 2$

\section{References}

I B.W. Weinberger, An Introduction to the History of Dentistry, vol. 1, Mosby Co., St Louis, 1948

2 J.A. Donaldson, Gold Bull., 1980, 13, (3), 117-124

3 R.L, Coleman, Dent, Cosmos, 1926, 68, 743-764

4 M.H. Campbell, Dent. Cosmos, 1860, 1, 638-639

5 A. Wilm, Metallurgie, 1911, 8, 225-227

6 E.M. Wise, W. Crowell and J.T. Eash, Trans. Met. Soc. AlME., 1932, 99 363-412

7 E.M. Wise and J.T. Eash, Trans. Met, Soc. AIME., 1933, 104, 276-307

8 K.F. Leinfelder, W.J. O'Brien and D.F. Taylor, J. Dent. Res, 1972, 51, (4), 900-905

9 K.F. Leinfelder and D.F. Taylor, J. Dent, Res., 1977, 56, (3), 335-345

10 L. Nowack, Z. Metallkde., 1930, 22,94-103 \& $202415 / 418$

11 D. Harker, Trans. ASM., 1944, 32, 210-238

12 G.C. Kuczynski, R.F. Hoclıman and M. Doyama, J. Appl. Phys., 1955 , 26, $871-878$

13 M. Hirabayashi and S. Weissmann, Acta Met, 1962, 10, 25-36

14 C.H. Joharsson and J.O. Linde, Ann. Physik, 1936, 25, $1-48$

15 S. Ogawa and D. Watanabe, J. Phys. Soc. Jpn., 1954, 9, 475-488

I6 S. Ogawa, D. Watanabe, H. Watanabe and T. Komoda, Acta Cryst., 1958, $11,872-875$

17 D.W. Pashley and A.E. Presland, J. Inst. Met., 1958/59, 87, 419-428

18 A.B. Glossop and D.W. Pashley, Proc. Roy. Soc., 1959, A250, 132-146

19 S. Ogawa, D. Watanabe, H. Watanabe and T. Komoda, J. Phys. Soc. Jpn., $1959,14,936-941$

20 H. Sato and R.S. Toth, Phys. Rev., 1961, 124, 1833-1847

21 L. Stemer-Rainer, Z. Metallkde., 1925, 17, (5), 162-165

22 G. Masing and K. Kloiber, Z. Metallkde, 1940, 32, (5), 125-132

23 J. McMullin and J. Norton, Met. Trans., 1949, 1, (1), 46-48

24 E. Raub, Z. Metallkde., 1949, 40,46-54 820 2350

25 R. Hultgren and L. Tarnopol, Trans. Met. Soc. AIME., 1939, 133, 228-238

26 M. Murakami, D. de Fontaine, J. Sanchez and J. Fodor, Thin Solid Films, $1975,25,465-482$
27 T. Uzuka, Y. Kanzawa and K. Yasuda, J. Dent. Res., 1981, 60, (5), 883-889

28 R. Kikuchi, J. Sanchez, D. de Fontaine and H. Yamauchi, Acta Met., $1980,28,651-622$

29 H. Yamauchi, H.A. Yoshimatsu, A.R. Forouhi and D. de Fontaine, 'Phase relation in Cu-Ag-Au ternary alloys', Proc. $4 \mathrm{th}$ Int. Prec. Met. Conf., Toronto, Canada, Pergamon Press, 1980, 241-249

30 O. Shashikov, V. Syutkina and V. Rudenko, Phys. Met. Metallogi., 1955 , 37, 119-128

31 Y. Kanzawa, K. Yasuda and H. Metahi, J. Less-Comm. Met., 1975, 43, $121-128$

32 A. Prasad, T. Eng and K. Mukherjee, Mater. Sci. Eng., 1976, 24, 179-185

33 K. Yasuda, H. Metahi and Y. Kanzawa, J. Less-Comm. Met., 60, 65-78

$34 \mathrm{~K}$. Yasuda and M. Ohta, 'Age-Hardening in a 14 carat dental gold alloy', Proc. 3rd Int. Prec. Met. Conf., Chicago, IL., IPMI., 1979, 137-164

35 K. Yasuda and M. Ohta, J. Dent. Res., 1982, 61, (3), 473-479

36 M. Ohta, T. Shiraishi, M. Yamane and K. Yasuda, Dent. Mater, J., 1983, $2,10-17$

37 K. Yasuda, M. Nakagawa, G, Van Tendeloo and S. Amelinckx, J. Less-Comm. Met., 1987, 135, (2), 169-183

38 D. Watanabe and K. Takashima, J. Appl. Cryst., 1975, 8, 598-602

39 K. Yasuda and Y. Kanzawa, Trans. Jpn. Inst. Met., 1977, 18, (1), 46-54

$40 \mathrm{~K}$. Yasuda and M. Ohta, J. Less-Comm. Met., 1980, 70, 75-87

41 K. Yasuda, K. Udoh. K. Hisatsune and M. Ohta, Dent. Mater. J., 1983, 2 , (1), 48-58

42 K. Udoh, K. Hisatsune, K. Yasuda and M. Ohta, Dent. Mater. J., 1984 3, (2), 253-261

43 K. Udoh, K. Yasuda and M. Ohta, L. Less-Comm. Met, , 1986, 118, 249-259

44 K. Yasuda, G. Van Tendeloo, J, Van Landuyt and S. Amelinckx, J. Dent, Res., 1986, 65, (9), 1179-1185

45 G. Van Tedeloo and S. Amelinckx, Phys. Stat. Sol (a), 1981, 65, 431-446 